\title{
Best of Both Worlds: A Comparison of Canadian and International Best Practices for Hospital Pharmacy Services
}

\author{
Angela Wright, Régis Vaillancourt, Jean-François Bussières, Denis Lebel, Elaine Wong, \\ David Mancini, and Diana Sarakbi
}

\section{INTRODUCTION}

I Canada, pharmacy practice is governed by legislation, by codes of ethics, and by professional regulatory authorities, which prescribe minimum standards of practice for pharmacists in their respective provinces. ${ }^{1}$ In addition, a variety of organizations promote best practices for medication management in Canada and internationally. In particular, the following organizations have helped shape hospital pharmacy practice through their standards, goals and objectives, or statements for providing safe, high-quality pharmacy services: Accreditation Canada, the Canadian Society of Hospital Pharmacists (CSHP), and the International Pharmaceutical Federation (FIP).

Accreditation Canada is an independent, not-for-profit organization that offers accreditation programs and services for organizations across the health care continuum. ${ }^{2}$ The current accreditation program, Qmentum, is designed to promote an organization-wide approach toward safety and quality improvement. ${ }^{3}$

Medication management is one of the core set of standards within Qmentum. These standards promote a collaborative approach to maintaining a medication management system that involves pharmacy services and representatives from across the organization to help prevent and reduce medication errors. ${ }^{4}$ In 2013, Accreditation Canada enhanced the language and restructured the standards to reflect the key steps in developing an effective medication management system. Revisions also included promoting a collaborative approach to medication management, addressing risks associated with the increased use of technology, and raising awareness about reporting adverse drug reactions. The standards now consist of 11 themes (outlined in Table 1), with 27 standards comprising 148 detailed criteria. Accreditation Canada has also identified medication reconciliation as a Required Organizational Practice (ROP) in the Qmentum program. Accreditation Canada defines an ROP as an essential practice that organizations must have to enhance patient safety.
Compliance with the standards is evaluated by means of a peer-review model, whereby Accreditation Canada surveyors identify strengths and areas for improvement during an on-site organizational survey.

The CSHP is a national voluntary organization of pharmacists that maintains goals and objectives for advancing pharmacy practice in hospitals and other collaborative health care settings. The organization promotes best practices, information sharing, research, and recognition of excellence in pharmacy services. ${ }^{5}$ In 2008, CSHP launched the "CSHP 2015 Targeting Excellence in Pharmacy Practice" initiative to improve patient safety and medication-related outcomes in hospitals and related health care settings. ${ }^{6}$ CSHP identified 6 goals that focus on the roles and responsibilities of pharmacists in improving medication safety by 2015 (Table 1). These goals are subdivided into 36 objectives that describe how to achieve each goal.

The FIP is the global federation of national associations of pharmacists and pharmaceutical scientists. ${ }^{8}$ It aims to "improve global health by advancing pharmacy practice and science to enable better discovery, development, access to and safe use of appropriate, cost-effective, quality medicines worldwide". ${ }^{8}$ In 2008, the Hospital Pharmacy Section of FIP developed a set of consensus statements based on input from 348 hospital pharmacists representing 98 nations. ${ }^{8}$ The FIP "Basel statements" recognize that medication safety is a multilevel effort requiring commitment at the national, regional, hospital, and pharmacist levels to create an ideal, global vision for hospital pharmacy practice. A total of 75 statements are grouped into 7 themes (as listed in Table 1). ${ }^{8}$ These statements are used internationally to drive change and to guide advancements in pharmacy practice. ${ }^{9-14}$

In 2008, CSHP published a "crosswalk" indicating how the CSHP 2015 goals and objectives aligned with other Canadian and international medication-related initiatives, including the standards set by Accreditation Canada and FIP. ${ }^{15}$ The CSHP 


\section{Table 1. Comparison of Accreditation Canada, CSHP, and FIP Themes for Pharmacy Practice}

\section{Accreditation Canada 2013 Medication Management Standards}

- Planning the medication management system

- Training and competency evaluation

- Accessing client and medication information

- Selecting and procuring medications

- Storing medications in the pharmacy and client service areas

- Prescribing and ordering medications

- Preparing medications

- Labelling and packaging medications

- Dispensing and delivering medications

- Administering medications and client monitoring

- Evaluating the medication management system

\section{CSHP 2015 Goals and Objectives}

2008 FIP Basel statements

- Increase the extent to which pharmacists help individual hospital inpatients achieve the best use of medications

- Increase the extent to which pharmacists help individual non-hospitalized patients achieve the best use of medications

- Increase the extent to which hospital and related healthcare setting pharmacists actively apply evidence-based methods to the improvement of medication therapy

- Increase the extent to which pharmacy departments in hospitals and related healthcare settings have a significant role in improving the safety of medication use

- Increase the extent to which hospitals and related healthcare settings apply technology effectively to improve the safety of medication use

- Increase the extent to which pharmacy departments in hospitals and related healthcare settings engage in public health initiatives on behalf of their communities

CSHP = Canadian Society of Hospital Pharmacists, FIP = International Pharmaceutical Federation

crosswalk identified 31\% alignment with the Accreditation Canada standards and 53\% alignment with the FIP Basel statements. ${ }^{15}$ However, the most recent update of this comparison occurred in 2011, and it does not reflect the latest version of the Accreditation Canada medication management standards, released in 2013. It also does not assess alignment between the Accreditation Canada standards and the FIP Basel statements. The current study was undertaken to update the crosswalk and to provide a more detailed comparison of these practice standards. The main objective of this study was therefore to evaluate the degree of alignment among the best practices for pharmacy services recommended by Accreditation Canada, CSHP, and FIP.

\section{METHODS}

Two of the authors (R.V., D.M.) created crosswalks outlining preliminary alignment between the Accreditation Canada standards, the CSHP 2015 goals and objectives, and the FIP Basel statements. Although the 2011 CSHP crosswalk was used as a starting point, the crosswalks for the current study were developed primarily by independent review of each best-practice standard.

A panel of 4 pharmacists, including 2 of the authors (D.L., E.W.), was recruited to evaluate the proposed alignment in the preliminary crosswalks. Panel members were recruited on the basis of their familiarity with the process and standards of Accreditation Canada and the goals and objectives of the CSHP 2015 initiative. The pharmacists were asked to rate each pair of statements using the following 3-point Likert scale: $1=$ no similarity, 2 = some similarity, and 3 = sufficient similarity.

Descriptive statistics were generated from the panel's ratings. A statement was classified as being "aligned" if at least $75 \%$ of the panel (i.e., 3 of the 4 panel members) assigned a rating of 2 ("some similarity") or 3 ("sufficient similarity"). A global alignment score was then calculated for each crosswalk and each theme in the crosswalk based on the number and proportion of statements for which alignment was confirmed.

\section{RESULTS}

\section{Alignment with Accreditation Canada 2013 Medication Management Standards}

Of the 149 Accreditation Canada criteria (including the ROP for medication reconciliation covered in the Accreditation Canada service-delivery standards), 75 (50\%) were initially aligned with one or more of the FIP Basel statements in the preliminary crosswalk. Of these 75 criteria with initial alignment, $69(92 \%)$ achieved $75 \%$ agreement (i.e., some or sufficient similarity) with at least one FIP Basel statement. Overall, 69 (46\%) of the 149 Accreditation Canada criteria were categorized as being aligned with one or more of the FIP Basel statements.

In contrast, 25 (17\%) of the 149 Accreditation Canada criteria were initially aligned with one or more of the CSHP 2015 objectives. Of these 25 criteria with initial alignment, 23 (92\%) achieved $75 \%$ agreement (i.e., some or sufficient similarity) with at least one CSHP objective. Overall, 23 (15\%) of the 149 
Accreditation Canada criteria were classified as being aligned with one or more of the CSHP objectives.

The results for alignment of the Accreditation Canada 2013 Medication Management Standards are summarized by theme in Table 2.

\section{Alignment with CSHP 2015 Goals and Objectives}

Of the 36 CSHP 2015 objectives, 21 (58\%) were initially aligned with one or more of the FIP Basel statements. All 21 of these objectives achieved $75 \%$ agreement (i.e., some or sufficient similarity) with at least one FIP Basel statement, and therefore were classified by the panel as being aligned.

Sixteen (44\%) of the 36 CSHP 2015 objectives were initially aligned with one or more of the Accreditation Canada criteria. Of these 16 objectives with initial alignment, 15 (94\%) achieved $75 \%$ agreement (i.e., some or sufficient similarity) with at least one Accreditation Canada criterion. Overall, 15 (42\%) of the 36 CSHP objectives were classified as being aligned with one or more of the FIP Basel statements.

The results for alignment of the goals and objectives of the CSHP 2015 initiative are summarized by theme in Table 3.

\section{Alignment with FIP Basel Consensus Statements}

Of the 75 FIP Basel statements, 60 (80\%) were initially aligned with one or more of the Accreditation Canada criteria.
Of these 60 statements, 50 (83\%) achieved 75\% agreement (i.e., some or sufficient similarity) with at least one Accreditation Canada criterion. Overall, 50 (67\%) of the 75 FIP Basel statements were classified as being aligned with one or more of the Accreditation Canada criteria.

Thirty (40\%) of the 75 FIP Basel statements were initially aligned with one or more of the CSHP 2015 objectives. Of these 30 statements, $25(83 \%)$ achieved $75 \%$ agreement (i.e., some or sufficient similarity) with at least one CSHP 2015 objective. Overall, 25 (33\%) of the 75 FIP Basel statements were classified as being aligned with one or more of the CSHP 2015 objectives.

Results for alignment of the FIP Basel consensus statements are summarized by theme in Table 4 .

\section{DISCUSSION}

More than $80 \%$ of the statements in each crosswalk with initial alignment were subsequently rated by at least $75 \%$ of the panel as having "some similarity" or "sufficient similarity". These results indicate that the panel agreed overall that the crosswalks of the Accreditation Canada standards, CSHP 2015 goals and objectives, and FIP Basel statements showed alignment.

The results revealed variation in the degree of alignment between the Accreditation Canada standards, the CSHP 2015 goals and objectives, and the FIP Basel statements. The highest level of overall alignment was $67 \%$ for the crosswalk comparing

Table 2. Alignment with Accreditation Canada Medication Management Standards by Theme

\begin{tabular}{|c|c|c|c|c|}
\hline \multirow{3}{*}{$\begin{array}{l}\text { Accreditation Canada } 2013 \text { Medication } \\
\text { Management Standards } \\
\text { Planning the medication management } \\
\text { system }(n=23)\end{array}$} & \multicolumn{4}{|c|}{ No. (\%) of Standards Aligned* } \\
\hline & \multicolumn{2}{|c|}{$\begin{array}{l}\text { With } 2008 \text { FIP Basel } \\
\text { Statement Themes }\end{array}$} & \multicolumn{2}{|c|}{$\begin{array}{l}\text { With CSHP } 2015 \text { Goals } \\
\text { and Objectives }\end{array}$} \\
\hline & 15 & $(65)$ & 7 & $(30)$ \\
\hline Training and competency evaluation $(n=4)$ & 1 & $(25)$ & 0 & $(0)$ \\
\hline $\begin{array}{l}\text { Accessing client and medication information } \\
(n=18)\end{array}$ & 14 & $(78)$ & 4 & $(22)$ \\
\hline Selecting and procuring medications $(n=14)$ & 7 & $(50)$ & 0 & (0) \\
\hline $\begin{array}{l}\text { Storing medications in the pharmacy and } \\
\text { client service areas }(n=14)\end{array}$ & 6 & (43) & 0 & (0) \\
\hline Prescribing and ordering medications $(n=9)$ & 2 & $(22)$ & 1 & $(11)$ \\
\hline Preparing medications $(n=12)$ & 6 & $(50)$ & 2 & $(17)$ \\
\hline Labelling and packaging medications $(n=6)$ & 3 & $(50)$ & 0 & $(0)$ \\
\hline Dispensing and delivering medications $(n=12)$ & 2 & $(17)$ & 2 & $(17)$ \\
\hline $\begin{array}{l}\text { Administering medications and client monitoring } \\
(n=21)\end{array}$ & 5 & (24) & 3 & (14) \\
\hline $\begin{array}{l}\text { Evaluating the medication management system } \\
(n=15)\end{array}$ & 7 & $(47)$ & 3 & (20) \\
\hline Medication reconciliation $\operatorname{ROP}(n=1)$ & 1 & $(100)$ & 1 & $(100)$ \\
\hline Total $(n=149)$ & 69 & $(46)$ & 23 & (15) \\
\hline \multicolumn{5}{|c|}{$\begin{array}{l}\text { CSHP = Canadian Society of Hospital Pharmacists, FIP = International Pharmaceutical Federation, } \\
\text { ROP = required organizational practice in Accreditation Canada service-delivery standards. } \\
{ }^{*} \text { A standard from the Accreditation Canada } 2013 \text { medication management standards was considered } \\
\text { to be aligned with the } 2008 \text { FIP Basel statements or the goals and objectives of the CSHP } 2015 \\
\text { initiative if } 3 \text { of } 4 \text { panel members (75\%) assigned a rating of } 2 \text { ("some similarity") or } 3 \text { ("sufficient } \\
\text { similarity"). }\end{array}$} \\
\hline
\end{tabular}


Table 3. Alignment with CSHP 2015 Goals and Objectives by Theme

\begin{tabular}{|c|c|c|}
\hline \multirow[b]{2}{*}{ CSHP 2015 Goals and Objectives by Theme } & \multicolumn{2}{|c|}{ No. (\%) of Objectives Aligned* } \\
\hline & $\begin{array}{l}\text { With } 2008 \text { FIP Basel } \\
\text { Statement Themes }\end{array}$ & $\begin{array}{l}\text { With Accreditation } \\
\text { Canada } 2013 \text { Medication } \\
\text { Management Standards }\end{array}$ \\
\hline $\begin{array}{l}\text { Increase the extent to which pharmacists help } \\
\text { individual hospital inpatients achieve the best } \\
\text { use of medications }(n=5)\end{array}$ & $5 \quad(100)$ & $4 \quad(80)$ \\
\hline $\begin{array}{l}\text { Increase the extent to which pharmacists help } \\
\text { individual non-hospitalized patients achieve the } \\
\text { best use of medications }(n=4)\end{array}$ & $1 \quad(25)$ & $1 \quad(25)$ \\
\hline $\begin{array}{l}\text { Increase the extent to which hospital and related } \\
\text { healthcare setting pharmacists actively apply } \\
\text { evidence-based methods to the improvement of } \\
\text { medication therapy }(n=9)\end{array}$ & $2 \quad(22)$ & $1 \quad(11)$ \\
\hline $\begin{array}{l}\text { Increase the extent to which pharmacy } \\
\text { departments in hospitals and related healthcare } \\
\text { settings have a significant role in improving the } \\
\text { safety of medication use }(n=8)\end{array}$ & $7 \quad(88)$ & $5 \quad(63)$ \\
\hline $\begin{array}{l}\text { Increase the extent to which hospitals and } \\
\text { related healthcare settings apply technology } \\
\text { effectively to improve the safety of medication } \\
\text { use }(n=6)\end{array}$ & $6 \quad(100)$ & $4 \quad(67)$ \\
\hline $\begin{array}{l}\text { Increase the extent to which pharmacy } \\
\text { departments in hospitals and related healthcare } \\
\text { settings engage in public health initiatives on } \\
\text { behalf of their communities }(n=4)\end{array}$ & (0) & (0) \\
\hline Total $(n=36)$ & $21 \quad(58)$ & $15 \quad(42)$ \\
\hline
\end{tabular}

Table 4. Alignment with FIP Basel Statements by Theme

No. (\%) of Statements Aligned*

\begin{tabular}{rrrr}
\hline $\begin{array}{c}\text { With Accreditation } \\
\text { Canada 2013 Medication } \\
\text { Management Standards }\end{array}$ & $\begin{array}{c}\text { With CSHP 2015 } \\
\text { Goals and Objectives }\end{array}$ \\
\hline 9 & $(56)$ & 11 & $(69)$ \\
7 & $(78)$ & 0 & $(0)$ \\
4 & $(57)$ & 4 & $(57)$ \\
9 & $(100)$ & 2 & $(22)$ \\
14 & $(88)$ & 2 & $(13)$ \\
7 & $(88)$ & 4 & $(50)$ \\
0 & $(0)$ & 2 & $(20)$ \\
50 & $(67)$ & 25 & $(33)$ \\
\hline
\end{tabular}

CSHP = Canadian Society of Hospital Pharmacists, FIP = International Pharmaceutical Federation. *A statement from the 2008 FIP Basel statements was considered to be aligned with the Accreditation Canada 2013 medication management standards or the goals and objectives of the CSHP 2015 initiative if 3 of 4 panel members (75\%) assigned a rating of 2 ("some similarity") or 3 ("sufficient similarity").

the FIP Basel statements with the Accreditation Canada criteria. The lowest level of overall alignment was $15 \%$ for the crosswalk comparing the Accreditation Canada criteria with the CSHP 2015 objectives.

In the comparison of Canadian standards, only 15\% of the Accreditation Canada criteria were found to be aligned with the CSHP 2015 objectives. The following Accreditation Canada themes were not aligned with any of the CSHP 2015 objectives: training and competency evaluation, selecting and procuring medications, storing medications in the pharmacy and client service areas, and labelling and packaging medications. Conversely, 42\% of the CSHP 2015 objectives were aligned with the Accreditation Canada criteria. The only CSHP 2015 theme that was not aligned with at least one Accreditation Canada criterion 
was the involvement of the pharmacist in public health initiatives. This level of alignment represents an improvement over that reported by the 2011 CSHP crosswalk ${ }^{15}$ (42\% versus $31 \%$ ) and may reflect convergence of the best practices of Accreditation Canada and CSHP through the 2013 update to the Accreditation Canada standards.

The low level of alignment between the Canadian standards may be explained by differences in focus between Accreditation Canada and the CSHP 2015 initiative in relation to pharmacy services. The CSHP 2015 objectives identify specific pharmacy and therapeutic goals to be achieved by hospital pharmacists in institutional settings, whereas the Accreditation Canada criteria provide a more comprehensive, organization-wide view of quality and safety in medication management. As a result, the goals identified by CSHP 2015 do not address the effect of system requirements, such as the selection, procurement, storage, labelling, or packaging of medications, and training on an organization's medication management systems. In contrast to the focus of the CSHP 2015 initiative, these themes reflect an organization-wide approach to medication management and are not specific to the pharmacist providing patient care. In addition, Accreditation Canada has separate standards dedicated to public health services, which helps to explain the lack of alignment with this CSHP 2015 theme. Overall, then, the Accreditation Canada standards and the CSHP 2015 goals and objectives seem to offer complementary views of hospital pharmacy practice in Canada.

In the analysis of alignment between Canadian and international standards, the panel determined that $67 \%$ of the FIP Basel statements were aligned with at least one of the Accreditation Canada criteria, whereas only 33\% were aligned with the CSHP 2015 objectives. However, both the Accreditation Canada criteria and the CSHP 2015 objectives achieved alignment with at least one of the FIP Basel statements in 6 of the 7 themes. The Accreditation Canada standards did not align with the FIP theme related to human resources and training, while the CSHP 2015 objectives were not aligned with the procurement theme of the FIP Basel statements.

The human resources and training theme in the FIP Basel statements outlines initiatives for improving pharmacy practice that can be undertaken at the national, regional, and hospital levels. These statements are outside the scope of the Accreditation Canada medication management standards, which focus on an organization's role in ensuring medication safety. Instead, this theme is covered in Accreditation Canada's leadership standards, which address human resource requirements at the organizational level.

The lack of alignment of the CSHP 2015 objectives with the procurement theme in the FIP Basel statements highlights the focus of the CSHP 2015 initiative on the role of hospital pharmacists in providing patient care, not on the medication management system.

Alignment of the FIP Basel statements with the standards of the American Society of Health-Systems Pharmacists (ASHP) has been previously described. ${ }^{16}$ The authors of that study found that $88 \%$ of the FIP Basel statements were aligned with one or more of the ASHP standards, and this included alignment within each of the FIP themes. ${ }^{16}$ It was therefore expected that similar results would be observed with the CSHP 2015 objectives, as CSHP and ASHP have similar roles and focus in their respective countries. However, the FIP Basel statements had a greater degree of alignment with the ASHP standards than with the CSHP 2015 objectives. This may be because the ASHP standards cover additional requirements related to policy positions and practice standards that are not addressed by the CSHP 2015 objectives. ${ }^{17}$ In addition, the alignment between ASHP and FIP statements was determined by only 2 authors, ${ }^{16}$ whereas the current study used a panel of 4 raters.

About half of the Accreditation Canada standards and the CSHP 2015 objectives were aligned with at least one FIP Basel statement ( $46 \%$ and $58 \%$, respectively). The $58 \%$ alignment of CSHP 2015 objectives with FIP consensus statements is similar to the $53 \%$ reported in the previous CSHP crosswalk..$^{15}$ All of the Accreditation Canada themes had at least one criterion that aligned with the FIP Basel statements. However, the FIP Basel statements did not cover the CSHP 2015 objectives for involvement of pharmacists in public health initiatives, as these are not within the scope of the hospital pharmacy section of the FIP Basel statements. Instead, public health initiatives are addressed in the joint FIP and World Health Organization guidelines on good pharmacy practice. ${ }^{18}$

Hospital pharmacy practice in Canada has evolved since the publication, in 2008, of both the FIP Basel statements and the CHSP 2015 goals and objectives, as evidenced in part by the publication of the current Accreditation Canada medication management standards in 2013. Despite this evolution, these statements, goals and objectives, and standards remain relevant to current hospital pharmacy practice, as seen by the overall alignment among the themes covered by the FIP Basel statements, the Accreditation Canada standards, and the CSHP goals and objectives. These similarities reflect a common vision between Canadian and international best practices for pharmacy services.

\section{Limitations}

This evaluation had some limitations. Only 2 people determined initial alignment, and the 4 raters determined levels of agreement with this initial alignment. If more people had been involved in creating and rating the degree of alignment, there might have been less inter-rater variability in support of the initial alignment. A larger group of raters would also have helped to determine if the arbitrary cut-off of at least $75 \%$ of raters assigning "some similarity" or "sufficient similarity" was appropriate, as it would have been easier to identify outlying responses.

Another limitation was the subjectivity of determining alignment between standards from various organizations. Different interpretations of the statements, standards, and objectives, as well as the rating scale used, may have affected the results. For 
example, one of the raters indicated that if a statement from one organization included the word "pharmacist" and the statement being compared for alignment did not include that word, a rating of "no similarity" was automatically assigned. This conservative approach on the part of at least one of the raters may have contributed to a lower level of alignment between the standards.

\section{CONCLUSION}

The differences noted between the Accreditation Canada 2013 medication management standards, the CSHP 2015 goals and objectives, and the 2008 FIP Basel consensus statements reflect the different focus of each organization in relation to hospital pharmacy practice. Whereas the Accreditation Canada standards stem from an organization-wide approach to ensuring a safe, high-quality medication management system, CSHP 2015 focuses solely on the role of hospital pharmacists. FIP provides a more global view by identifying medication safety initiatives at the national, regional, hospital, and pharmacist levels. Despite these differences in perspective, common themes emerged around the role of the pharmacist in providing safe, high-quality care. This information may assist hospital pharmacies in prioritizing their efforts to achieve the common standards, goals and objectives, and statements from these various organizations, representing a common vision for hospital pharmacy practice and excellence in patient care.

\section{References}

1. About NAPRA. Ottawa (ON): National Association of Pharmacy Regulatory Authorities; (C) 2009 [cited 2014 Aug 12]. Available from: http://napra.ca/ pages/About/default.aspx

2. Strategic plan 2014 to 2016. Ottawa (ON): Accreditation Canada; [cited 2014 Feb 24]. Available from: www.accreditation.ca/sites/default/files/ strategic-plan-2014-16-en.pdf

3. Qmentum. Ottawa (ON): Accreditation Canada; [cited 2014 Feb 24]. Available from: www.accreditation.ca/qmentum

4. Medication management standards. Ottawa $(\mathrm{ON})$ : Accreditation Canada [cited 2014 Aug 12]. Available to order from: www.accreditation.ca/ medication-management-standards

5. About us. Ottawa (ON): Canadian Society of Hospital Pharmacists; 2014 [cited 2014 Feb 26]. Available from: www.cshp.ca/aboutUs/ourMission_e.asp

6. CSHP 2015 - targeting excellence in pharmacy practice. Ottawa (ON): Canadian Society of Hospital Pharmacists; 2014 [cited 2014 Feb 26]. Available from: www.cshp.ca/cshp2015/index_e.asp

7. Canadian hospital pharmacy 2015 (CSHP 2015): CSHP goals and objectives for pharmacy practice in hospitals and related healthcare settings to be achieved by 2015. Ottawa (ON): Canadian Society of Hospital Pharmacists; 2007 [revised 2008; cited 2014 Feb 26]. Available from: www.cshp.ca/ dms/dmsView/2_CSHP-2015-Goals-and-Objectives-Feb-25\%2707-wAppdx-rev-May\%2708.pdf

8. Who we are and what we do. The Hague (Netherlands): International Pharmaceutical Federation; [cited 2014 Feb 26]. Available from: https:// www.fip.org/?page=menu_about

9. 2020 vision: FIP's vision, mission and strategic plan. The Hague (Netherlands): International Pharmaceutical Federation; [cited 2014 Feb 26]. Available from: www.fip.org/files/fip/strategic\%20plan\%20no\%20annexes.pdf

10. The Basel statements on the future of hospital pharmacy. Am J Health Syst Pharm. 2009;66(5 Suppl 3):S61-6.

11. Poh J, Vaillancourt R, Lamarre D, Oyella J. Use of the 2008 Basel consensus statements to assess, realign, and monitor pharmacy practice at a tertiary care hospital in northern Uganda: illustrative case study. Can J Hosp Pharm. 2013;66(5):318-27.
12. Savio E, Fernández G, Olmos V, Daners M, Gerpe N. FIP Basel statements and the future of hospital pharmacy services in Uruguay. Int Pharm J. 2010;26(2):39-41.

13. Jiang D, Wang Y, Yan S, Lin X, Guo H, Wang Y. A comparison of Chinese hospital pharmacy practice and the Basel statements. Int Pharm J. 2010; 26(2):42-4.

14. Nordor RB, Tetteh RA. Current status of the Basel statements and work of hospital pharmacists in Ghana. Int Pharm J. 2010;26(2):47-8.

15. CSHP 2015 crosswalk. Ottawa (ON): Canadian Society for Hospital Pharmacists; [revised 2011; cited 2014 Feb 26]. Available from: www.cshp.ca/ dms/dmsView/1_Crosswalk-2011-Revision-FINAL-\%282\%29---Nov2011.pdf

16. Zellmer WA, Hawkins B. The Basel Statements as stimulus for advancement of hospital pharmacy in a developed country. Int Pharm J. 2010;26(2):44-6.

17. About us. Bethesda (MD): American Society of Health-Systems Pharmacists; 2014 [cited 2014 Feb 26]. Available from: www.ashp.org/menu/AboutUs

18. Annex 8: Joint FIP/WHO guidelines on good pharmacy practice: standards for quality of pharmacy services. WHO Tech Rep Ser 961. Geneva (Switzerland): World Health Organization; 2011 [cited 2014 Feb 26]. p. 310-23. Available from: www.who.int/medicines/areas/quality_safety/quality_ assurance/FIPWHOGuidelinesGoodPharmacyPracticeTRS961Annex8.pdf

Angela Wright, BSc, BScPhm, PharmD, was, at the time of this study, a PharmD student in the Leslie Dan Faculty of Pharmacy, University of Toronto, Toronto, Ontario; she completed a PharmD rotation at the Children's Hospital of Eastern Ontario, which allowed participation in the project. She is now a Pharmacy Resident at St Joseph's Healthcare Hamilton, Hamilton, Ontario.

Régis Vaillancourt, BPharm, PharmD, is Director of Pharmacy at the Children's Hospital of Eastern Ontario, Ottawa, Ontario.

Jean-François Bussières, BPharm, MSc, FCSHP, is Director of the Pharmacy Department and the Pharmacy Practice Research Unit, Centre hospitalier universitaire Sainte-Justine, and Clinical Professor with the Faculty of Pharmacy, Université de Montréal, Montréal, Quebec.

Denis Lebel, BPharm, MSc, FCSHP, is Assistant Director of the Pharmacy Department and the Pharmacy Practice Research Unit, Centre hospitalier universitaire Sainte-Justine, Montréal, Quebec.

Elaine Wong, BScPhm, is Medication Safety Pharmacist at the Children's Hospital of Eastern Ontario, Ottawa, Ontario.

David Mancini, BSC, is a Pharmacy Student at the University of Waterloo, Waterloo, Ontario. He worked on this project during a co-op placement at the Children's Hospital of Eastern Ontario.

Diana Sarakbi, BSc, MBA, is a Program Development Specialist with Accreditation Canada, Ottawa, Ontario.

\section{Competing interests: None declared.}

\section{Address correspondence to:}

Dr Régis Vaillancourt

Director of Pharmacy

Children's Hospital of Eastern Ontario

401 Smyth Road

Ottawa ON K1H $8 \mathrm{~L} 1$

e-mail: rvaillancourt@cheo.on.ca

Acknowledgement: The authors would like to acknowledge Geneviève Goulet and Miriam McDonald, who generously donated their time to evaluate the proposed "crosswalk" documents.

Funding: Medbuy facilitated the discussion that formed the basis for this project. 